\title{
VENTILATION AND PUBLIC HEALTH
}

\author{
By D. D. Kimball,
}

Of Richard D. Kimball Company, Mechanical and Electrical Engineers, New York.

\section{Importance of Ventilation}

Air is more essential to life than food, good air is as essential as good food, and plenty of air has the same merit as plenty of food. Unlike food air cannot be had in too great quantities, and an inexhaustible supply of pure air is always available. Being invisible and unfelt we give it no thought, and thus we have come to give little or no heed to its condition. That air quality has a definite relation to comfort and health is never denied, but that means must always be provided to assure proper quality of air in our habitations still fails to find general assent; in other words, ventilation, artificial or natural, as a means of providing fresh air, is still denied proper recognition. This may in part be due to the mistaken idea largely prevailing that artificial ventilation can do for health and comfort all that nature's boundless resources can do, whereas ventilation at its best is but an attempt to approach within doors, as near as may be, nature's outdoor conditions.

Ventilation would make far greater headway if the public dicl but realize how closely allied ventilation is to individual health. In but few of the relations of life are we free from contact with the public. Whether it be in our homes with our guests, with our children in the schools, traveling in street cars, railway cars or boats, at the opera, concert or church, with the sick in the hospitals, or with the workers in the factories and stores, we are brought so intimately into contact with the public that the health of any part thereof has a definite bearing on the health of the whole.

Ventilation is closely connected with cleanliness. Few of us would care to put on underclothing immediately taken from another person, bathe in water used by another, or put into our mouths articles of food or drink taken from another's mouth, yet we take into our lungs with but little or no hesitation air containing that 
which has but just come from other people's mouths and lungs or from close contact with their bodies and soiled clothing.

Experiments of Buchner, Flugge and others have shown that tubercle bacilli and other organisms are sprayed through a room from the mouth, for a distance of many feet and over wide areas, when men talk or cough. In case of infuenza, conditions in railway and other cars, churches and living rooms, all may be infected who are not immune.

The public is just beginning to learn of the wonderful results obtained in hospital work with the introduction of outdoor work and wards, but does not yet recognize that the nearer indoor conditions in hospitals are made to approach outdoor conditions by means of the most ample ventilation the better will be the results. When one considers that there are 3,000,000 persons sick in the United States, and that the percentage of cures is increased, and the average length of illness is decreased by ventilation, the public importance of pure air becomes evident.

The benefit of plenty of fresh air is strikingly seen in openair treament of tuberculosis. Patients well advanced in the disease, who for months or even years have spent their time bundled up indoors, sitting over stoves or registers, afraid of a breath of cool air, and who under this regime cough continually, sleep poorly and have no appetite, after being required to stay in the open air for twenty-four hours each day, and to sleep in tents or open shacks, in a week's time cease the constant cough, sleep and eat well, put on flesh and look like different creatures. Outdoor treatment of pneumonia, anaemia, nervous and other diseases is equally beneficial.

Probably no place in which people gather is the need of ventilation as a protection to the public greater than in the factory, store and mercantile establishment, nevertheless the vast majority of these are utterly devoid of ventilation of any kind; indeed, as examples of badly ventilated habitations, they are supreme. Persons in charge of factories know they would be blamed were employees to complain that they had taken cold from open windows, while they are not held responsible for sickness due to vitiated air and overheating. The ample protection of health and life in the industries is a matter of humanitarian obligation on the part of the employer and the public, as well as a question of self-interest on the part of the employee. Ventilation cannot properly be regarded 
as a high-priced luxury to be enjoyed by the privileged few, but should rather be regarded as a priceless benefit to be enjoyed by all. No investment yields larger returns than that required for ventilation.

\section{The Problem of Ventilation}

Ventilation is the process of supplying fresh air and removing so far as possible the vitiated air. The air supply must be clean and free from dust, must be of the proper temperature and humidity, sufficient quantity of air must be secured by proper air movement without injurious drafts; and poisonous gases like carbonic oxide from heating or lighting apparatus must be prevented. Air must be supplied without loss of its freshness.

Air is the medium for carrying oxygen into the lungs, its office being to oxidize the excretions from the blood vessels therein. Oxygen is thus the element of the air that is of the greatest importance to human beings. It is essential in both heating and ventilating work, being the active element in combustion and in the similar processes which go on within the human lungs where it acts upon the carbon and impurities in the blood, forming the chemical compounds which are thrown off during respiration.

Fresh air is taken into the lungs containing approximately $2 \mathrm{I}$ per cent oxygen, 78 per cent nitrogen, .04 per cent carbonic acid, and .ol per cent water vapor. The process of respiration changes the composition of the air breathed to approximately 16 per cent oxygen, 75 per cent nitrogen, 4 per cent carbonic acid and 5 per cent water vapor. Oxygen is reduced in amount while the carbonic acid and water vapor are largely increased. Oxygen is utilized for body building, and carbonic acid and water vapor are the products given off during respiration.

Neither water vapor nor the carbonic acid due to respiration is injurious; but as an increase of carbonic acid in the air of an occupied apartment is usually accompanied by a decrease in the amount of oxygen and an increase of water vapor, the percentage of carbonic acid is an index of the quality of the air.

Apparently it is not altogether the chemistry of the air, but its temperature, humidity, motion and possibly other physical properties unknown, which are the attractive features of outdoor air. It is becoming to be generally believed that when air contains a 
normal proportion of oxygen, its temperature and humidity are of greater importance than the absence of carbonic acid.

The over-heating of dwellings and public buildings should be avoided. The proper control of the temperature is not alone conducive to health and comfort but means a substantial saving in fuel. Headaches, dizziness, sickness, etc., are often symptoms of heat retention due chiefly to highroom temperature and humidity. It is not uncommon to find houses, offices, etc., in which the temperature sometimes reaches $80^{\circ}$, and yet the occupants can hardly be convinced that the temperature is high, because of the fact that the percentage of moisture in the air is very low. Few of us realize the intimate relation of temperature and humidity, and many people do not appreciate that water vapor is as much a part of the air as oxygen.

The relative humidity of outdoor air at other times than during storms varies from 50 per cent to 80 per cent, and in the most arid desert is rarely as low as 30 per cent, while a relative humidity of 48 per cent, that of Denver, is considered very dry.

Air at zero and 50 per cent relative humidity contains less than a quarter of a grain of moisture per cubic foot. The same air warmed to $70^{\circ}$ without the addition of moisture would have a relative humidity of but 3 per cent. Its absorptive capacity is, therefore, immensely increased.

If air on a day on which the outside temperature is zero and the relative humidity 50 per cent be passed through a furnace, and raised to $70^{\circ}$, the relative humidity of the air in a house will be 10 per cent to 20 per cent or dryer than the air of the driest desert known. If a room at $68^{\circ}$ is not warm enough for a healthy person we may be sure it is because the relative humidity is too low, except in rare cases when the humidity is so high, $i$. $e .80$ per cent or above, that the moisture in the air rapidly absorbs heat from the body, under which conditions one may complain of chilliness even with high temperature. It is unscientific and unsatisfactory to determine upon a temperature for comfort without regard to humidity.

With outdoor weather conditions of zero, and 50 per cent relative humidity, the proper ventilation of a schoolroom containing forty pupils will require the addition to the air of approximately thirty-eight pounds, about five gallons, of water each hour, requiring 
for its evaporation, the consumption of approximately five pounds of coal per hour. The fact that there are very few schools with means of humidification is less an argument to be used against such provision than an impeachment of the prevailing methods of schoolroom ventilation.

The remarkable avidity of dry warm air for moisture causes it to extract moisture from everything with which it comes into contact, and when the tissues and delicate membranes of the respiratory tract are subjected to this drying process a large increase of work is placed upon the mucous glands. This unnatural stimulation may result in an enlargement of the gland tissues, just as constant exercise increases the size of any part of the animal organism. The membrane itself may become thickened and harsh, and the surface prepared for the reception of disease germs, which tend to develop under exposure to the constantly changing percentages of humidity. Not alone are the throat and lungs affected; the tongue, lips and skin become feverish and parched, the eyes redden and smart, the ears are unnaturally dried; catarrh is induced, or is aggravated if already existing. In the case of children predisposed to lung diseases a serious hacking cough is apt to result. Overdry air causes headaches, robs all of vitality, and in every way lowers the vital powers. Generally speaking dry air is an excitant, sometimes causing sleeplessness and irritability, while moist air seems balmy and has a soothing effect which tends to produce restfulness and sleep.

A proper relative humidity lessens the evaporation from the surface of the body and thus the body remains warmer, consequently with air of a relative humidity of 50 per cent to 60 per cent. it is both possible and comfortable to lower the temperature of the house to $65^{\circ}$, schools to $62^{\circ}$, and the temperature of public buildings may be lowered similarly.

The idea that a lessening of the room temperature when raising the relative humidity will result in economy in heating is in error. It takes much more heat (which means fuel) to evaporate the water required to increase the relative humidity than to heat the air $5^{\circ}$ or $10^{\circ}$.

The children in the schools with a proper relative humidity are much healthier and consequently are able to think and remember better. Capable officials have determined that the working capacity 
of factory operatives is definitely increased in air of proper relative humidity.

It is a sad commentary on our modern civilization that we wilfully allow the health of the school children and the public generally to suffer for the lack of proper moisture while the manufacturer whose commercialism tells him that relative humidity is important to the success or profits of his manufacturing process will provide necessary humidifying apparatus.

Dust is another serious problem in ventilation. Many ventilating systems are worse than useless because the air is taken in at or below the street level or from other dust-contaminated sources, and is passed into the building without filtration, the result being that the last state of the building is worse than the first.

There are two phases to the dust question: the mechanical effect of dust, and its germicidal properties. Careful investigations have demonstrated that dust, especially street dust, is heavily laden with germs, the majority of which are harmless but others are of a most serious nature. Carried into the respiratory tract they lodge in soil splendidly adapted to the propagation of germ life. Dust is a serious irritant, and when drawn into the nasal passages, throat and lungs, may cause irritation and even abrasions. The mortality from consumption is known to be very much greater among persons employed in the so-called dusty trades than among those who work in the open air, or under otherwise more sanitary and favorable conditions affecting health and life. Some trades involve processes in which dust, fumes, vapors, odors, excessive heat and poisons are produced which are really injurious and which are properly removed in but rare cases.

Windows and doors may be depended upon for ventilation of buildings only when it is evident that a sufficient current of air passes through to give thorough ventilation and without causing drafts which strike and chill a portion of the body of those who are insufficiently clad. If sufficient air is not naturally passing through the windows and doors, air movement should be assured by mechanical means.

Drafts and cold are too commonly associated with "colds." Breezes which bathe the whole body not only bring unlimited supplies of the purest air but have a tonic effect. Cold air does not cause "colds." Arctic explorers rarely, if ever, have colds. It 
is during the winter months that outdoor treatments are the most successful. The places most to be feared are not out of doors, in hallways and in fresh air currents, but in vitiated atmospheres such as are common to ill-ventilated schools, theatres, churches, railway cars and wherever overcrowding occurs. Drafts of this vitiated air are a menace. Dust, leading to disease infection, is more frequently the cause of colds than fresh air drafts. Unquestionably there exists a misunderstanding of the nature and effect of fresh air drafts and a fear often akin to fright. A weakened vitality, harboring disease germs, may be wonderfully toned up by frequent and generous drafts of fresh air, or to an equal extent may be injured by a lesser movement of vitiated air. A hot, shut-up house is little more than a hot house for the propagation of bacilli and disease germs. Out-of-door life in plenty, ample exercise, and thorough ventilation of indoors may be depended upon to give practical immunity from drafts as commonly known.

While the use of natural ventilation is to be encouraged in every way possible, it may not be depended upon in our climate to the exclusion of artificial ventilation in school buildings, except in special cases where outdoor or similar treatment is desirable, hospitals, churches, factories and other crowded apartments. However, a system of artificial ventilation which is deranged by the opening of windows or doors is hardly worthy the name. On the other hand the reckless opening of windows does not constitute ventilation.

A popular impression seems to exist that warm air is not fresh air. If a distinction be made between warm air and hot or superheated air there is no ground for such an impression. Properly admitted, filtered and warmed, the air supplied by a ventilating system lacks in nothing but quantity. The air must not be so highly heated as to rob it of its freshness, nor must it be laden with traces of ammonia, carbon monoxide or other objectionable gases which may be produced by decomposition of organic dust in contact with surfaces at unnecessarily high temperatures.

In large buildings it is often advisable to distinguish between "heating" and "ventilating," accomplishing the first by means of direct radiators and the second by a suitable indirect system. The designing engineer is, however. confronted with the fact that too often the ventilating system will not be used if the direct radiators 
will heat the building,-more shame to the owner whose pocketbook causes him to forget the health and vigor of which the ventilating plant is the conveyor.

Ventilation, like all things good, costs money, indeed it costs more than the heating of the building without ventilation, but in schools, hospitals, offices, and in all such places it is the best possible investment and the one which will bring the greatest returns in increased work done and in improved efficiency generally.

\section{Results Accomplished by Ventilation}

Professor Irving Fisher, of Yale University, in addressing the Association of Life Insurance Presidents, stated that, "It has been conservatively calculated that eight years could be added to the normal period of human life by merely securing reasonably pure air, water and milk." The statement is also made that one insurance company pays $\$ 800,000$ annually for death claims on account of tuberculosis alone, which is known to be preventable, principally by the use of plenty of fresh air.

The reports of the Boston City Hospital show that improved general sanitary conditions in that institution changed the death rate from forty-four per cent to thirteen per cent. In the general wards of the same hospital the sanitary improvements effected changed the death rate from twenty-three to six per cent, or nearly in the same ratio as in the surgical wards.

At the S. R. Smith Infirmary, at Staten Island, a comparison was made in two wards of the same nature, containing the same class of patients, in which case it was found that in the ward without ventilation an average of sixteen days was required to effect a cure while in the ventilated wards the average was ten days. This also means a greater work with the same equipment.

Examples are available showing the improvements in results and health due to ventilation, but the time element is so important in such investigations that tests are rare and difficult to make.

Dr. J. N. Hurty, Secretary of the State Board of Health, Indiana, is authority for the statement that, "In properly heated, ventilated and lighted schoolrooms in Richmond. Evansville, and other cities in Indiana, we have secured an efficiency in the pupils of twenty-five per cent over what it was under old conditions. How much of this increased efficiency is due to better ventilation we 
cannot say, but the entire increase must be credited to ventilation, proper lighting and even distribution of heat, and regular temperature. We have found through a system of marking and grading pupils that those who work under the best sanitary conditions will accomplish in three years what they ordinarily accomplish in four."

The Germania Insurance Company of New York, in I9ro, had eighty clerks in one office. Previous to the proper ventilation thereof, ten per cent were absent on account of illness all the while. Since then, absenteeism has been reduced practically to nothing.

The vice-president of the Manhattan Trust Company of New York states that by proper ventilation he has so increased the efficiency of his clerical force that he has been able to reduce the number of employees four per cent.

The records of the United States Pension Bureau show that when the offices of the department were located in scattered and poorly ventilated buildings, 18,736 days were lost by employees through illness in one year and about the same number for several successive years. When the department became established in new well-ventilated quarters, the loss was reduced to IO, I I4 days' absence on account of illness, although the working force was much larger.

In the printing establishment of Mr. C. J. O'Brien, in New York, a ventilation system was installed because of the insistence of the State Department of Labor that the law be complied with, the order having been resisted for two years. After the system had been in use a year the proprietor stated that had he known in advance of the results to be obtained no order would have been necessary to have brought about the installation. Whereas formerly the men had left work on busy days in an exhausted condition and sickness was common, now the men left work on all days in an entirely different condition, and sickness had been very much reduced. The errors in typesetting and time required for making corrections were greatly reduced.

Townsend, Grace \& Co., of Baltimore, built a straw hat factory without ventilating apparatus. The first two winters after occupation the sick rate was twenty-seven and one-half per cent. A ventilating system was then installed, after which the winter sick rate fell to seven per cent. It was claimed that the ventilating system paid for itself in one year. 
In Strouse Brothers' clothing factory, of Baltimore, the sick rate was reduced about one-half by the installation of an inferior ventilating system.

The army medical officers gave some of the earliest definite data on air quantities required in ventilation work and have furnished many illustrations of the value of ventilation, as has also the naval service. Munson records: "The medical officer at Fort Douglass, in 1898 , reported an inmediate decrease in the number of cases of tonsilitis among the troops at that post on installing suitable arrangements in the previously improperly ventilateri barracks."

\section{Legislation as to Ventilation}

Much has been written on the value of ventilation, but little has been accomplished toward bringing adequate relief from present oppressive conditions to those who are least able to demand it, the children in the schools, the workers in the factories, and the dwellers in the congested districts.

But seven states (Massachusetts, New York, New Jersey, Pennsylvania, Virginia, Utah and Minnesota) have school ventilation laws, and but three (Connecticut, Vermont and Indiana) have state board of health rulings requiring ventilation of school buildings, but not one of them refers to the subjects of dust, humidity, or source of air supply. These laws, however, are a big step in advance, and every state should have a law at least as good. Compulsory ventilation laws are under consideration in Illinois, Indiana and Wisconsin. Twenty-one states have laws governing factory ventilation, the most of the laws referring to removal of special dust, fumes, etc., rather than to air supply, its quality or quantity, and but one law covers conditions in mercantile establishments. But very few of these laws are of real merit. A few cities have local urdinances of doubtful value. Such laws should be made to include all classes of buildings that are densely occupied, such as court houses, hospitals, asylums, reformatories, houses of refuge, prisons, schools, colleges, theatres, auditoriums, factories, stores and all places where people congregate. They should state the minimum air supply (quality and quantity) and removal, prescribe the official who has authority to administer the law, and they should 
include provisions for the removal of all dusts in a sanitary manner. Humidity and temperature should be prescribed where possible.

But a very feeble beginning of a most important movement has thus far been made. It may properly be considered a form of the ever-growing police power of the people, to be exercised for the welfare of the defenseless. It should be encouraged and participated in by all those interested in the welfare of humanity, and especially those bodies having to do with the public health, the welfare of the workers and the interests of the children. Every parent has the right to demand that the school, in which the child spends approximately one-fifth of its time for a large portion of the year, be thoroughly ventilated and in sanitary condition. No hospital should be considered worthy of use or patronage in which an effort at thorough and systematic ventilation, both natural and artificial, is not fundamentally a part of the equipment and service. Constant agitation is essential in this as in other worthy reforms. The prevailing ignorance of the worth of ventilation and the indifference of the public are the greatest handicaps in the onward progress of ventilation. The physician, to the success of whose work ventilation will so largely contribute, should realize the value of ventilation. Some doctors, and among them some hospital experts, fail to recognize the limitations of natural ventilation and the need of supplementing it with an efficient artificial ventilation system.

\section{The Architect Should be Aided by the Sanitary Engineer}

It is unfortunate for the progress of ventilation that much skepticism has been aroused as to the efficacy of artificial ventilating systems because of faulty installations made in the past. The too prevalent impression that ventilation is not an exact science is largely due to the fact that owners will too often accept as an expert any plumber or steamfitter who can put out his shingle and who claims to be a heating and ventilating engineer. Ventilating work should be designed by experienced engineers who are independent of any interest in contracting work or materials, and should be installed by contractors of equal merit in their line, under the supervision of the designer.

Improper operation of systems when installed has injured the cause of ventilation. The responsibilities of operating a venti$(46 \mathrm{t})$ 
lating plant costing thousands of dollars, the economical or efficient use of hundreds of tons of coal, and above all the keeping of the health of hundreds of school children, or of an equal number of sick or well adults, and the custody of their working efficiency, demand higher qualifications than those necessary for the shoveling of coal and ashes or the wielding of the deadly feather duster.

The architect for a new building should be provided by the owner with the assistance of expert engineering services covering the heating, ventilating and similar equipment. For this is it just and proper that the architect be paid extra by the owner and that he should not be left dependent upon the help of contractors or manufacturers of materials whose interests are naturally not those of the owner? Too many people expect the architect to be artist, designer, constructionist, landscape gardener, civil, mechanical, electrical and sanitary engineer, chemist, lawyer, jury and judge. The erection of a modern public building involves an architectural problem dealing with design and construction, and it also involves engineering problems requiring familiarity with the entirely different problems presented by air, water and steam in their different conditions and relations to each other. In brief, one problem is architectural and another engineering in its nature, the two involving different training and experience.

What this paper has attempted to show may be summarized as follows:

I. That all the fresh air possible should be given free access to the lungs by out-of-door living, and by natural ventilation of our habitations, breezes being less to be feared than vitiated air.

2. That artificial ventilation is absolutely essential as an aid to natural ventilation, that indoors may be kept in the best condition possible, $i$. e., as near as possible like out-of-doors.

3. That warm air (as distinguished herein from hot or superheated air) is equally as beneficial as cold air, lacking only in quantity, the matter of expense prescribing this limitation.

4. That the ventilating system which fails to take cognizance of the subjects of dust, humidity and temperature are foredoomed to failure, quality of air being quite as essential as quantity.

5. That efficient ventilating systems, fulfilling all of the above requirements, are available for all classes of buildings. The installation of such systems assumes the employment of experienced, independent engineers as distinguished from those connected with contracting or manufacturing firms. 
Efficient ventilation also involves the employment of capable operating engineers, resulting in efficiency and economy.

6. That dullness, restfulness, forgetfulness and general deficiency, being incident to a weakened vitality, are the results of the ill-ventilated schoolroom, while a quicker perception, improved memory, increased accomplishment, vigor, health and happiness go arm in arm with ample school-room ventilation.

7. That a lengthened illness and a lessened proportion of cures are chargeable to the insufficiently ventilated hospital, while the fresh air supplied by an efficient ventilating system is the angel of health bringing relief and healing to the weakened vitality.

8. That a poorer and a smaller output and more sick employees are the result of a foul-aired factory or mercantile establishment, while ventilation means less mistakes to be corrected, less idle machinery, and the maximum efficiency of plant and employees.

9. That the general ventilation of homes would mean less colds, catarrh and other preventable ills; and of auditoriums and places of entertainment would mean greater enjoyment on the part of the audience and an appreciable reduction in headaches and enervation.

Io. That the health of the individual largely determines the health of the public. The greater necessity for special ventilation where many people are assembled is due to heat and moisture given off and to the increased oxygen required. 